\title{
Speciation of Nitrogen Containing Aromatics by Atmospheric Pressure Photoionization or Electrospray Ionization Fourier Transform Ion Cyclotron Resonance Mass Spectrometry
}

\author{
Jeremiah M. Purcell, ${ }^{*}$ Ryan P. Rodgers, ${ }^{*}$ Christopher L. Hendrickson, ${ }^{*}$ \\ and Alan G. Marshall* \\ National High Magnetic Field Laboratory, Florida State University, Tallahassee, Florida, USA
}

We determine the elemental compositions of aromatic nitrogen model compounds as well as a petroleum sample by atmospheric pressure photoionization (APPI) and electrospray Ionization (ESI) with a 9.4 Tesla Fourier transform ion cyclotron resonance (FT-ICR) mass spectrometer. From the double-bond equivalents calculated for the nitrogen-containing ions from a petroleum sample, we can infer the aromatic core structure (pyridinic versus pyrrolic nitrogen heterocycle) based on the presence of $\mathrm{M}^{+}$(odd-electron) versus $[\mathrm{M}+\mathrm{H}]^{+}$(evenelectron) ions. Specifically, nitrogen speciation can be determined from either a single positive-ion APPI spectrum or two ESI (positive- and negative-ion) spectra. APPI operates at comparatively higher temperature than ESI and also produces radical cations that may fragment before detection. However, APPI fragmentation of aromatics can be eliminated by judicious choice of instrumental parameters. (J Am Soc Mass Spectrom 2007, 18, 1265-1273) (C) 2007 American Society for Mass Spectrometry

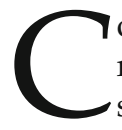
omplex organic mixture characterization by mass analysis requires the ultrahigh mass resolving power of Fourier transform ion cyclotron resonance mass spectrometry (FT-ICR MS) [1] to distinguish thousands of ionic species simultaneously $[2,3]$. Electrospray ionization (ESI) of polar analytes typically involves proton transfer reactions that selectively ionize acids (to produce negative $[\mathrm{M}-\mathrm{H}]^{-}$ions) or bases (to produce positive $[\mathrm{M}+\mathrm{H}]^{+}$ions) [3-6]. The ionization efficiency correlates with acidity or basicity. For example, carboxylic acids are efficiently ionized by negative-ion ESI, whereas basic species (e.g., pyridinic $\mathrm{N}_{1}$ species) are efficiently ionized by positive-ion ESI.

For non-polar aromatics, atmospheric pressure photoionization $[7,8]$ (APPI) can produce ions from species that are not efficiently ionized by ESI. The youngest of the soft ionization methods, dopant-assisted APPI, was initially developed to interface liquid chromatography to mass spectrometry to analyze simple mixtures. The ionization technique is ideal for non-polar aromatic compounds because the photon energy (typically $10 \mathrm{eV}$ ) is great enough to ionize aromatics but not non-

Address reprint requests to Dr. Alan G. Marshall, Florida State University, Ion Cyclotron Resonance Program, National High Magnetic Field Laboratory, 1800 East Paul Dirac Drive, Tallahassee, FL 32310-4005, USA. E-mail: marshall@magnet.fsu.edu

* Also with the Department of Chemistry and Biochemistry, Florida State University, Tallahassee, FL 32306-4390. aromatic solvents. However, direct photoionization is usually not efficient $[9]^{\circ}$ and $^{\circ}$ the $^{\circ}$ addition $^{\circ}$ of ${ }^{\circ} a^{\circ}$ dopant enhances ionization efficiency through proton-transfer reactions and charge-exchange reactions.

Although APPI is considered to be a soft ionization technique (i.e., produces minimal fragmentation of most analytes), it has been considered less soft than ESI because the APPI heated nebulizer and the source region can reach $>300^{\circ} \mathrm{C}$, whereas ESI is conducted at room temperature. Furthermore, toluene dopantassisted ${ }^{\circ} \mathrm{APPI}^{\circ}$ produces $^{\circ}$ radical $^{\circ}$ cations $^{\circ}[10]^{\circ}$ that $^{\circ}$ can participate in further gas-phase reactions.

Here, we compare ESI and APPI for analysis of petroleum crude oil (chosen because it represents the most complex organic mixture within a dynamic range of $1000-10,000)$. The nitrogen atom in aromatic $\mathrm{N}_{1}$ class species in petroleum can reside in a five-membered ring (pyrrolic) or six-membered ring (pyridinic) and be readily protonated (pyridinic) or deprotonated (pyrrolic) by positive-ion or negative-ion ESI, respectively [11]. ${ }^{\circ}$ However, ${ }^{\circ}$ positive-ion ${ }^{\circ} \mathrm{APPI}^{\circ}$ efficiently ${ }^{\circ}$ generates both pyrrolic and pyridinic nitrogen signals in a single mass $^{\circ}$ spectrum ${ }^{\circ}[12]$.

APPI can extend the characterization of the petroleome $^{\circ}\left[2,{ }^{\circ} 3\right]^{\circ}$ to $^{\circ}$ include $^{\circ}$ non-polar ${ }^{\circ}$ aromatic $^{\circ}$ species $^{\circ}$ and enhance the extent of molecular speciation for better understanding of petroleum processing and refining. The nitrogen class species are efficiently ionized by both 
ESI and APPI, and therefore offer a good basis for comparison. In this work, we couple APPI and ESI to a $9.4^{\circ}$ Tesla $^{\circ} \mathrm{FT}^{-\mathrm{ICR}^{\circ} \text { mass }^{\circ} \text { spectrometer }}{ }^{\circ}[13]^{\circ}$ for $^{\circ}$ detailed compositional comparison of the ions produced from the same South American crude oil.

\section{Experimental}

\section{South American Crude Oil}

South American crude oil was supplied by ExxonMobil Research and Engineering Company (Annandale, NJ, USA) and a sample (2.8 g) was fractionated according to the saturates-aromatics-resins-asphaltenes (SARA) method $^{\circ}[14]^{\circ}{ }^{\circ}$ The ${ }^{\circ}$ SARA $^{\circ}$ method $^{\circ}$ produced $^{\circ}$ an ${ }^{\circ}$ aromatic fraction solution of $100 \mathrm{mg} / \mathrm{mL}$ in toluene. Two serial dilutions yielded a $2 \mathrm{mg} / \mathrm{mL}$ solution that was further diluted in toluene to $1 \mathrm{mg} / \mathrm{mL}$ for APPI analysis and 1 $\mathrm{mg} / \mathrm{mL}$ in toluene:methanol (1:1 vol $/ \mathrm{vol})$ for ESI analysis.

\section{Nitrogen Class Compounds}

Five aromatic nitrogen compounds (acridine, carbazole, 7,9-dimethylbenz[c]acridine, 7H-dibenzo[c,g]carbazole and ellipticine) were purchased from Sigma-Aldrich (St. Louis, MO, USA). Equimolar solutions (2 mM) of the five nitrogen compounds were prepared in toluene. For ESI, the $2 \mathrm{mM}$ solutions were diluted by a factor of 5 in toluene to $400 \mu \mathrm{M}$ and, subsequently, equal aliquots $(100 \mu \mathrm{L})$ of the five compound solutions were combined and diluted with methanol $(1: 1 \mathrm{vol} / \mathrm{vol})$ to produce a final concentration of $40 \mu \mathrm{M}$ for each compound. For APPI, equal aliquots $(2 \mathrm{~mL})$ of $2 \mathrm{mM}$ solutions were combined to yield $400 \mu \mathrm{M}(10 \mathrm{~mL})$ for each compound, followed by a 1:10 dilution to $40 \mu \mathrm{M}$ for each analyte.

\section{FT-ICR Mass Spectrometry}

With our previously described 9.4 T FT-ICR mass spectrometer $\left[13,{ }^{\circ} 15\right]^{\circ}$ and $^{\circ}$ experimental ${ }^{\circ}$ conditions $^{\circ}[12]$, multiple (100-200) time-domain acquisitions were averaged for each sample, Hanning-apodized, and zerofilled once before fast Fourier transform and magnitude calculation ${ }^{\circ}[16]^{\circ}{ }^{\circ}$ Negative-ion ${ }^{\circ}$ data $^{\circ}$ were $^{\circ}$ collected $^{\circ}$ with similar parameters and appropriate polarity changes. All observed ions were singly charged, based on the unit $m / z$ separation between ${ }^{12} C_{n}$ and ${ }^{13} C_{1}{ }^{12} C_{n-1}$ isotopic $^{\circ}$ variants $^{\circ}$ of $^{\circ}$ the ${ }^{\circ}$ same $^{\circ}$ elemental $^{\circ}$ composition $^{\circ}[17]$. Therefore, all mass spectral peaks are reported in Daltons rather than $\mathrm{m} / \mathrm{z}$.

\section{APPI Conditions}

The APPI source was supplied by ThermoFisher Scientific (San Jose, CA, USA). The vaporized analyte gas stream flows orthogonal to the mass spectrometer inlet (heated metal capillary) and the krypton vacuum UV lamp. The source was mounted to a custom-built interface to the first differentially pumped stage of the 9.4 Tesla FT-ICR mass spectrometer through a heated metal capillary [stainless steel, $750-\mu \mathrm{m}$ inner diameter (i.d.)]. A Harvard stainless steel syringe $(8 \mathrm{~mL})$ and syringe pump delivered solution to the heated nebulizer of the APPI source. In the APPI source, solvent flow rate was $50-100 \mu \mathrm{L} / \mathrm{min}$; the nebulizer heater was operated at $250-350{ }^{\circ} \mathrm{C}$ with carbon dioxide as the sheath gas at 550 $\mathrm{kPa}^{\circ}$ and ${ }^{\circ}$ the ${ }^{\circ}$ auxiliary ${ }^{\circ}$ gas $^{\circ}$ port $^{\circ}$ was $^{\circ}$ plugged ${ }^{\circ}[12]$.

\section{ESI Conditions}

One end of a 50- $\mu \mathrm{m}$ i.d. fused silica tube was ground to a ${ }^{9}$ point ${ }^{\circ}$ and ${ }^{\circ}$ ssed $^{\circ}$ as $^{\text {th }}$ the microelectrospray $^{\circ}$ source $[18]^{\text {to }}$ produce electrosprayed positive and negative ions. General conditions were: needle voltage, $2 \mathrm{kV}(-2 \mathrm{kV}$ negative-ion electrospray); tube lens, $350 \mathrm{~V}(-350 \mathrm{~V}$ negative-ion electrospray); and heated metal capillary current, 4.0 amperes. ESI negative-ion conditions were comparable to ESI positive-ion conditions.

Table 1. Homologous series of ions from a crude oil. Members of the series have the same $N_{1} S_{1}$ heteroatoms and the same calculated DBE value of 17.5, but differ in the number of $\mathrm{CH}_{2}$ groups. Each molecular formula (from which the DBE value is calculated from Eq. 1) is for an $(\mathrm{M}+\mathrm{H})^{+}$ion, not its neutral precursor.

\begin{tabular}{|c|c|c|c|c|c|c|}
\hline Carbon Number & Experimental Mass (Da) & DBE & $\begin{array}{l}\text { Molecular } \\
\text { Formula }\end{array}$ & Class & Calculated Mass (Da) & Error ppm \\
\hline 28 & 406.16243 & 17.5 & $\mathrm{C}_{28} \mathrm{H}_{24} \mathrm{~N}_{1} \mathrm{~S}_{1}$ & $\mathrm{~N}_{1} \mathrm{~S}_{1}$ & 406.16240 & 0.08 \\
\hline 29 & 420.17804 & 17.5 & $\mathrm{C}_{29} \mathrm{H}_{26} \mathrm{~N}_{1} \mathrm{~S}_{1}$ & $\mathrm{~N}_{1} \mathrm{~S}_{1}$ & 420.17805 & -0.02 \\
\hline 30 & 434.19366 & 17.5 & $\mathrm{C}_{30} \mathrm{H}_{28} \mathrm{~N}_{1} \mathrm{~S}_{1}$ & $\mathrm{~N}_{1} \mathrm{~S}_{1}$ & 434.19370 & -0.09 \\
\hline 31 & 448.20934 & 17.5 & $\mathrm{C}_{31} \mathrm{H}_{30} \mathrm{~N}_{1} \mathrm{~S}_{1}$ & $\mathrm{~N}_{1} \mathrm{~S}_{1}$ & 448.20935 & -0.02 \\
\hline 32 & 462.22501 & 17.5 & $\mathrm{C}_{32} \mathrm{H}_{32} \mathrm{~N}_{1} \mathrm{~S}_{1}$ & $\mathrm{~N}_{1} \mathrm{~S}_{1}$ & 462.22500 & 0.03 \\
\hline 33 & 476.24063 & 17.5 & $\mathrm{C}_{33} \mathrm{H}_{34} \mathrm{~N}_{1} \mathrm{~S}_{1}$ & $\mathrm{~N}_{1} \mathrm{~S}_{1}$ & 476.24065 & -0.04 \\
\hline 34 & 490.25633 & 17.5 & $\mathrm{C}_{34} \mathrm{H}_{36} \mathrm{~N}_{1} \mathrm{~S}_{1}$ & $\mathrm{~N}_{1} \mathrm{~S}_{1}$ & 490.25630 & 0.07 \\
\hline 35 & 504.27200 & 17.5 & $\mathrm{C}_{35} \mathrm{H}_{38} \mathrm{~N}_{1} \mathrm{~S}_{1}$ & $\mathrm{~N}_{1} \mathrm{~S}_{1}$ & 504.27195 & 0.10 \\
\hline 36 & 518.28764 & 17.5 & $\mathrm{C}_{36} \mathrm{H}_{40} \mathrm{~N}_{1} \mathrm{~S}_{1}$ & $\mathrm{~N}_{1} \mathrm{~S}_{1}$ & 518.28760 & 0.08 \\
\hline 37 & 532.30328 & 17.5 & $\mathrm{C}_{37} \mathrm{H}_{42} \mathrm{~N}_{1} \mathrm{~S}_{1}$ & $\mathrm{~N}_{1} \mathrm{~S}_{1}$ & 532.30325 & 0.06 \\
\hline 38 & 546.31905 & 17.5 & $\mathrm{C}_{38} \mathrm{H}_{44} \mathrm{~N}_{1} \mathrm{~S}_{1}$ & $\mathrm{~N}_{1} \mathrm{~S}_{1}$ & 546.31890 & 0.28 \\
\hline 39 & 560.33465 & 17.5 & $\mathrm{C}_{39} \mathrm{H}_{46} \mathrm{~N}_{1} \mathrm{~S}_{1}$ & $\mathrm{~N}_{1} \mathrm{~S}_{1}$ & 560.33455 & 0.18 \\
\hline
\end{tabular}




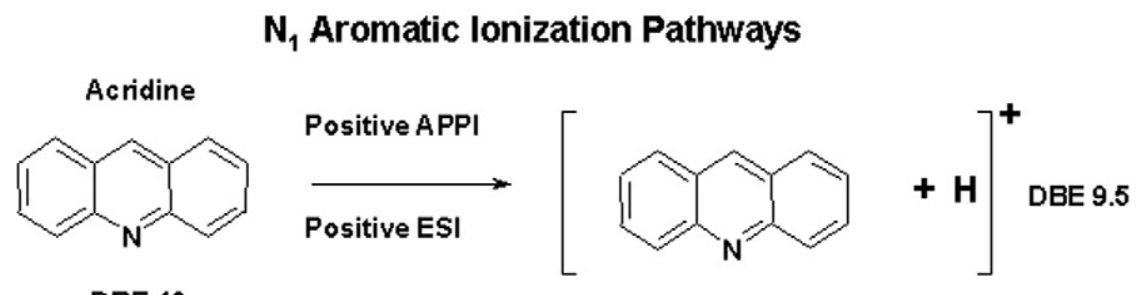

DBE 10

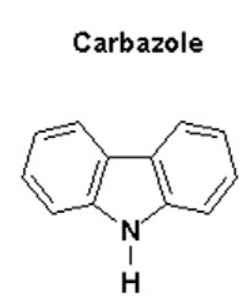

DBE 9<smiles>c1ccc2nc3ccccc3cc2c1</smiles>

Acridine

$\mathrm{C}_{13} \mathrm{H}_{3} \mathrm{~N} \quad$ MN 179.073

DBE 10

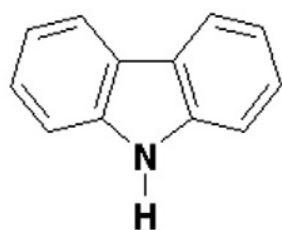

Carbazole

$\mathrm{C}_{12} \mathrm{H}_{9} \mathrm{~N} \quad \mathrm{MW} 167.073$

DBE 9

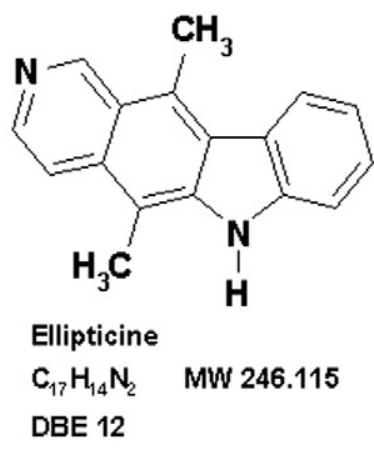

Negative ESI
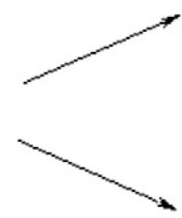

Positive APPI
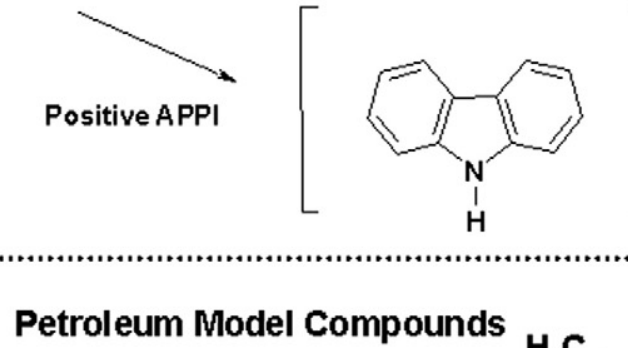

DBE 13

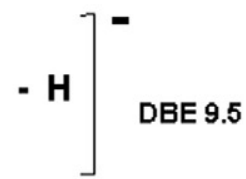

DBE 9<smiles>Cc1ccc2nc3c(ccc4ccccc43)c(C)c2c1</smiles>
7,9-dim ethylbenz[c]acridine $\mathrm{C}_{19} \mathrm{H}_{15} \mathrm{~N} \quad$ MN 257.120

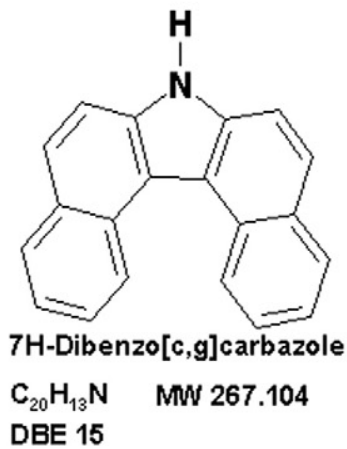

Figure 1. ESI and APPI ionization pathways for acridine and carbazole (top) and nitrogen class compounds (bottom). For ESI, negative-ion and positive-ion spectra would be necessary to detect both species. However, both compounds yield APPI positive ions. Double-bond equivalents (DBE) are calculated from eq 1 for each ion. For the nitrogen class compounds, carbazole and 7H-dibenzo[c,g]carbazole are pyrrolic (acidic), whereas acridine and 7,9-dimethylbenz[c]acridine are pyridinic (basic) species. Ellipticine, with two nitrogen heteroatoms, has both pyrrolic and pyridinic moieties. 


\section{Negative ESI}

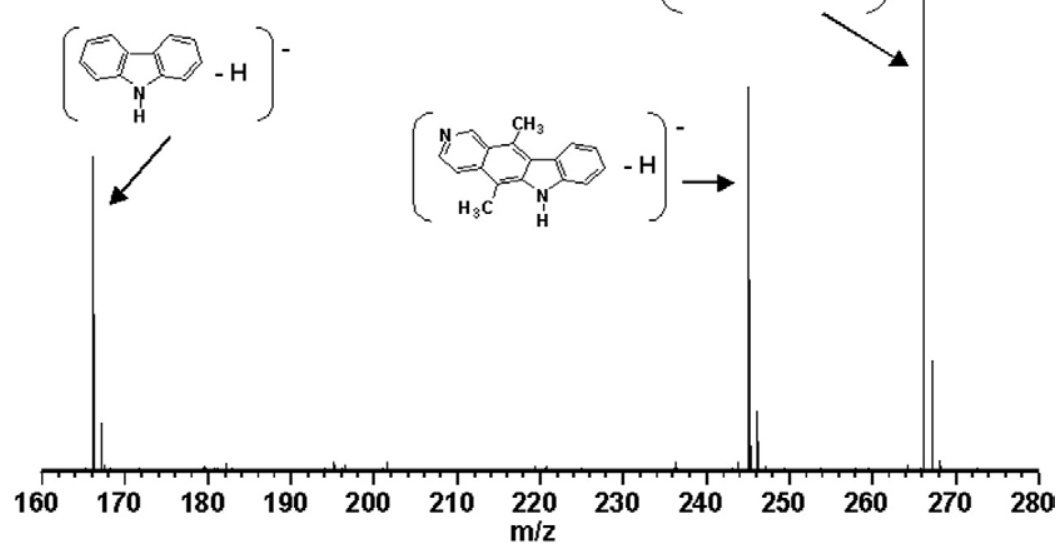

Positive ESI

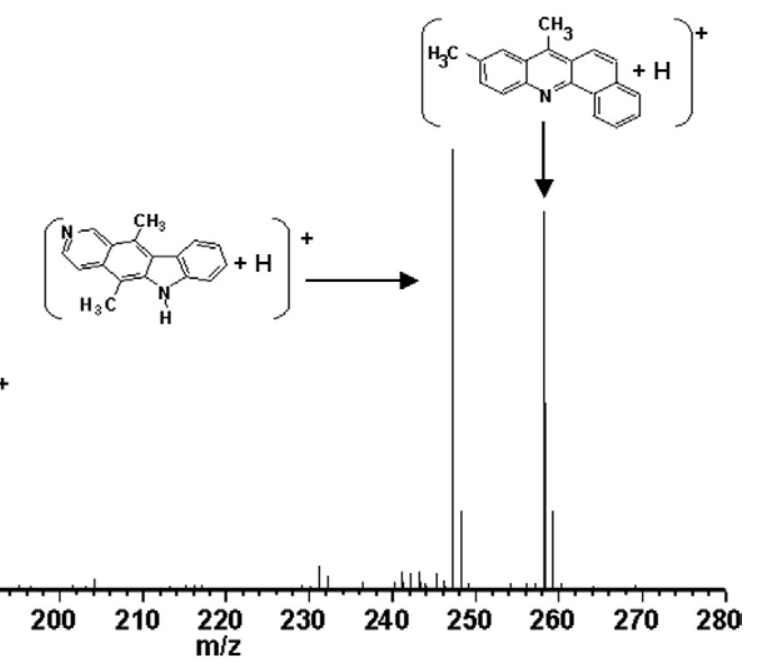

Figure 2. Negative-ion and positive-ion ESI FT-ICR mass spectra of representative nitrogen-class compounds. For both spectra, an equimolar solution was electrosprayed. The pyrrolic species were ionized by negative-ion ESI and the pyridinic species by positive-ion ESI. Ellipticine was detected in both negative-ion and positive-ion spectra.

\section{Double-Bond Equivalents Calculation}

Crude oil consists primarily of homologous series. Each homologous series is categorized by heteroatom class $\left(\mathrm{N}_{\mathrm{n}} \mathrm{O}_{\mathrm{o}} \mathrm{S}_{\mathrm{s}}\right)$, double-bond equivalents (DBE; see eq 1), and carbon number. The DBE is equal to the number of rings ${ }^{\circ}$ plus $^{\circ}$ double $^{\circ}$ bonds $^{\circ}$ and ${ }^{\circ}$ is $^{\circ}$ calculated $^{\circ}$ from $^{\circ}[19]$

$$
\operatorname{DBE}\left(\mathrm{C}_{\mathrm{c}} \mathrm{H}_{\mathrm{h}} \mathrm{N}_{\mathrm{n}} \mathrm{O}_{\mathrm{o}} \mathrm{S}_{\mathrm{s}}\right)=\mathrm{c}-(\mathrm{h} / 2)+(\mathrm{n} / 2)+1
$$

Within each heteroatom class, there are many DBE values. For example, $\mathrm{C}_{42} \mathrm{H}_{59} \mathrm{~N}_{1}$ belongs to the $\mathrm{N}_{1}$ class with $\mathrm{DBE}=14$, whereas $\mathrm{C}_{42} \mathrm{H}_{53} \mathrm{~N}_{1}$ belongs to the same heteroatom class, $\mathrm{N}_{1},{ }^{\circ}$ but ${ }^{\circ}$ its ${ }^{\circ} \mathrm{DBE}{ }^{\circ}$ is ${ }^{\circ} 17 .{ }^{\circ}$ Table ${ }^{\circ} 1^{\circ}$ shows the carbon number distribution (28-39) for the homologous members of the $\mathrm{N}_{1} \mathrm{~S}_{1}$ class with DBE 17.5 (pyridinic). All DBE values in this work are calculated from the molecular formula of the ion, so that odd-electron radical cations have integer DBE values, whereas pro- tonated or deprotonated (even-electron) ions have halfinteger DBE values.

\section{Results and Discussion}

\section{Nitrogen Compounds}

Figure $^{\circ} 1^{\circ}$ (top $)^{\circ}$ shows ${ }^{\circ}$ the $e^{\circ}$ possible ${ }^{\circ}$ ionization ${ }^{\circ}$ pathways for aromatic $\mathrm{N}_{1}$ class compounds (acridine and carbazole) by APPI (positive-ion) and ESI (negative-ion and positive-ion). The two pathways involving proton transfer yield even-electron $[\mathrm{M}+\mathrm{H}]^{+}$or $[\mathrm{M}-\mathrm{H}]^{-}$ions with half-integer DBE values. Positive-ion APPI can also form odd-electron radical cations with integer DBE values.

Five $^{\circ}$ nitrogen-containing ${ }^{\circ} \operatorname{aromatics}^{\circ}\left(\right.$ Figure $^{\circ} 1,{ }^{\circ}$ bottom) were selected as petroleum model compounds: two pyrrolic (five-membered ring), two pyridinic (six-membered ring), and one with one of each ring 
Negative APPI
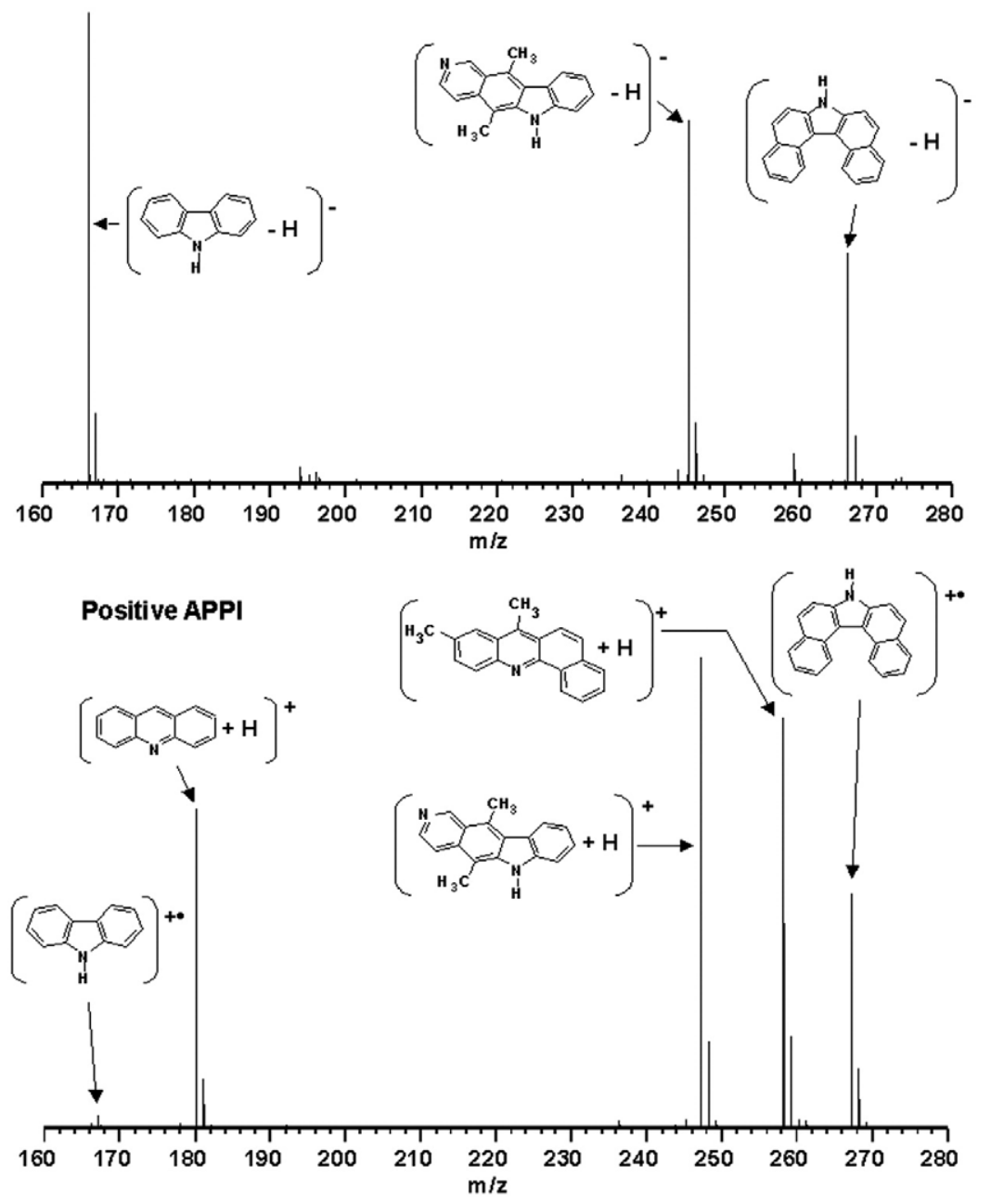

Figure 3. Negative-ion and positive-ion APPI spectra of representative nitrogen-class compounds. For both spectra, an equimolar solution was infused into the APPI source. The pyrrolic species were detected in the negative-ion APPI spectrum, and all five compounds were detected in the positive-ion APPI spectrum.

type $^{\circ}$ (ellipticine).$^{\circ}$ Figure $^{\circ} 2^{\circ}$ shows $^{\circ}$ the ${ }^{\circ}$ positive-ion (bottom) and negative-ion (top) ESI spectra of an equimolar solution of the nitrogen compounds. The pyrrolic nitrogen species deprotonate to form $[\mathrm{M}-\mathrm{H}]^{-}$ions, whereas the pyridinic species protonate to form $[\mathrm{M}+\mathrm{H}]^{+}$ions.

Figure $^{\circ} 3^{\circ}$ shows $^{\circ}$ positive-ion ${ }^{\circ}$ (bottom $)^{\circ}$ and ${ }^{\circ}$ negativeion (top) APPI spectra of an equimolar solution of the nitrogen compounds. Both positive and negative ions are formed simultaneously in the source, enabling detection of either positive or negative ions by appropriate instrument polarity changes and no source interruption. The APPI negative-ion spectrum shows the deprotonated pyrrolic species. However, in the APPI positive-ion spectrum, all five nitrogen compounds are detected simultaneously. The pyrrolic species form radical molecular ions and the pyridinic species form protonated compounds.

The pyrrolic compounds (carbazole and 7H-dibenzo- [c,g]carbazole) exhibit different ionization efficiency (and ion type) in negative-ion and positive-ion APPI mass ${ }^{\circ}$ spectra. ${ }^{\circ} \mathrm{Carbazole}^{\circ}\left(7.6^{\circ} \mathrm{eV}^{\circ} \text { ionization }^{\circ} \text { energy }\right)^{\circ}[20]^{\circ}$ forms radical molecular cations less efficiently than the more extensively conjugated $7 \mathrm{H}$-dibenzo[c,g]carbazole $\left(7.1^{\circ} \mathrm{eV}{ }^{\circ} \text { ionization }{ }^{\circ} \text { energy }\right)^{\circ}[20]^{\circ} .{ }^{\circ}{ }^{\circ}$ contrast $^{\circ} \mathrm{APPI}{ }^{\circ}$ generates much more similar $[\mathrm{M}-\mathrm{H}]^{-}$ion abundances for both $^{\circ}$ carbazoles $^{\circ}$ (Figure ${ }^{\circ},{ }^{\circ}$ top).

\section{Nitrogen Class Speciation}

Figure $^{\circ} 4^{\circ}$ is $^{\circ}$ the $^{\circ}$ positive-ion ${ }^{\circ} \mathrm{APPI}^{\circ}$ broadband ${ }^{\circ}$ mass spectrum of a South American crude oil, including various closely spaced mass doublets. First, a 3.4 $\mathrm{mDa}^{\circ}$ separation $^{\circ}\left(\text { zoom }^{\circ} \text { inset }^{\circ}{ }^{\circ}{ }^{\circ} \text { Figure }^{\circ} 4\right)^{\circ}$ results ${ }^{\circ}$ from two compounds that differ in elemental composition by $\mathrm{C}_{3}$ versus $\mathrm{SH}_{4}$, a common mass doublet for crude oil. That mass difference is also seen by electrospray 


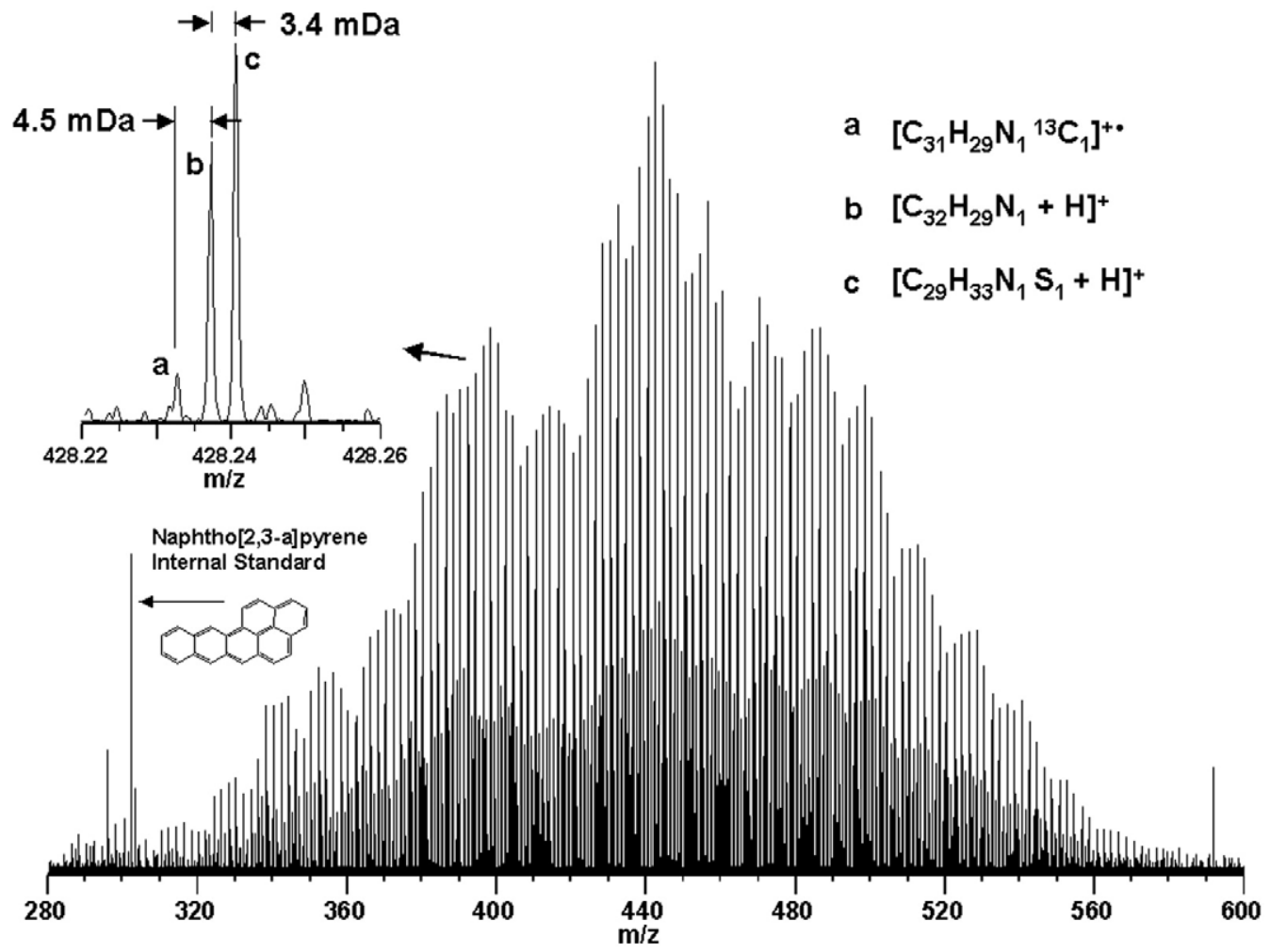

Figure 4. Positive-ion APPI FT-ICR broadband mass spectrum of a South American crude oil. Both radical molecular ions and protonated compounds are formed in the APPI source. The mass scale-expanded inset shows two common spectral peak doublets for APPI. Naphtho[2,3-a]pyrene was added to the petroleum sample to test for possible fragmentation. No fragment ions were observed.

ionization because both species can produce protonated compounds.

Second, APPI can produce an additional $4.5 \mathrm{mDa}\left({ }^{13} \mathrm{C}\right.$ versus $\left.{ }^{12} \mathrm{CH}\right)$ doublet not seen by ESI, as a result of formation of both a radical molecular ion $\left(\mathrm{M}^{+*}\right)$ and protonated molecule $\left([\mathrm{M}+\mathrm{H}]^{+}\right)$from the same neutral precursor. Naphtho[2,3-a]pyrene was added as a standard to test for fragmentation (see below); i.e., no spectral peaks corresponding to loss of one or two hydrogen atoms from naphtho[2,3-a]pyrene were observed.

The spectral peaks from the broadband spectrum were assigned unique molecular formulas based on accurate ${ }^{9}$ mass 9 measurement ${ }^{\circ}$ for ${ }^{\circ}$ omologous ${ }^{\circ}$ series $^{9}[21]$. Similar broadband spectra were acquired (data not shown) for both positive-ion and negative-ion ESI. The $\mathrm{N}_{1}$ class ions were sorted by DBE and carbon number. Figure ${ }^{\circ}{ }^{\circ}$ shows ${ }^{\circ} \mathrm{DBE}^{\circ}$ distributions ${ }^{\circ}$ for ${ }^{\circ} \mathrm{APPI}{ }^{\circ}$ positive-ion nitrogen class species and ESI negative- and positiveion nitrogen classes.

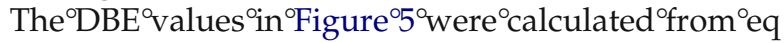
1 for the ion molecular formulas. Accordingly, halfinteger DBE values result for even-electron (protonated or deprotonated compound) ions, $[\mathrm{M}+\mathrm{H}]^{+}$or $[\mathrm{M}-\mathrm{H}]^{-}$, whereas integer DBE values result for odd-electron ions (e.g., radical cations, $\mathrm{M}^{+\cdot}$ ). Thus, the DBE value calculated from eq 1 for any $\mathrm{N}_{1}$-class aromatic compound readily distinguishes even-electron (pyridinic, half- integer DBE) from odd-electron (pyrrolic, integer DBE) ions produced by APPI.

From $^{\circ}$ the ${ }^{\circ} \mathrm{DBE}^{\circ}$ distribution ${ }^{\circ}$ (Figure ${ }^{\circ}{ }^{\circ},{ }^{\circ}$ top), ${ }^{\circ}$ clearly APPI produces both protonated compounds (halfinteger DBE) and radical molecular ions (integer DBE). Interestingly, the radical molecular ions begin at DBE 9, the same DBE threshold observed for negative even-electron $[\mathrm{M}-\mathrm{H}]^{-}$ions. In fact, if the negative-ion ESI DBE distributions are shifted onehalf DBE lower (to compensate for the one-proton difference in mass between $[\mathrm{M}-\mathrm{H}]^{-}$and $\mathrm{M}^{+}$), then the negative- and positive-ion ESI DBE distributions are essentially the same as the combined $[\mathrm{M}+\mathrm{H}]^{+}$ and $\mathrm{M}^{+\cdot}$ distribution from APPI.

Table $^{\circ} 2^{\circ}{ }^{1}$ ists $^{\circ}$ the $^{\circ}$ elemental $^{\circ}$ compositions $^{\circ}$ assigned to the APPI positive $\mathrm{N}_{1}$-class ions (DBE 9, pyrrolic) and ESI negative $\mathrm{N}_{1}$-class ions (DBE 9.5, pyrrolic). Note that the neutral molecular formulas are the same for both kinds of ions. The same behavior is seen throughout the nitrogen class DBE distributions-that is, the neutral elemental compositions inferred from the deprotonated (negative-ion) ESI ions are also seen for the positive-ion APPI ions at one-half integer lower DBE. Furthermore, the relative DBE abundances (APPI DBE 9 versus ESI DBE 9.5; Figure $\left.^{\circ} 5\right)^{\circ}$ agree $^{\circ}$ with $^{\circ}$ the ${ }^{\circ}$ nitrogen ${ }^{\circ}$ class $^{\circ}$ compound $^{\circ}$ spectra $^{\circ}\left(\right.$ Figures $^{\circ} 2^{\circ}$ and $^{\circ} 3$ ) - that ${ }^{\circ}$ is, ${ }^{\circ} a^{\circ}$ carbazole $^{\circ}$ type 


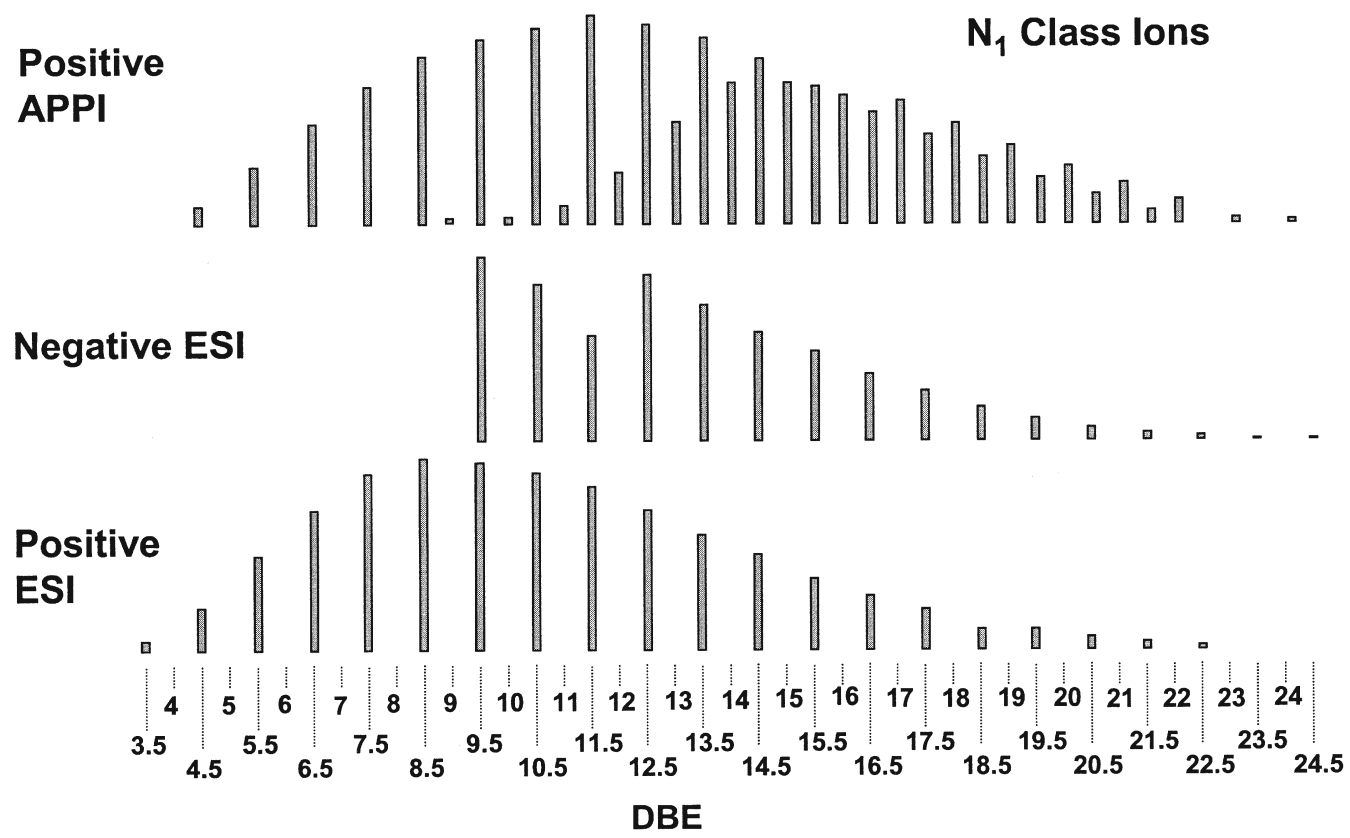

Figure 5. ESI (positive-ion and negative-ion) and APPI (positive-ion) DBE distributions for the $\mathrm{N}_{1}$ class from the petroleum sample. The ion DBE is calculated from eq 1. The total relative ion abundance for each DBE is plotted on the $y$-axis. For ESI, protonation or deprotonation yields ions of half-integer DBE values. For APPI, radical molecular ions yield integer DBE values. Note that positive-ion APPI can distinguish pyridinic $(\mathrm{M}+\mathrm{H})^{+}$from pyrrolic $\left(\mathrm{M}^{+\cdot}\right)$ nitrogen ions based on their respective half-integer and integer DBE values.

core structure compound will form a radical molecular ion (APPI positive-ion, 9 DBE) less efficiently (Figure $\left.{ }^{\circ},{ }^{\text {b bottom }}\right)^{\circ}$ than $^{\circ}$ in ${ }^{\circ}$ negative-ion ${ }^{\circ} \mathrm{ESI}^{\circ}\left({ }^{\circ} .5^{\circ} \mathrm{DBE}\right)$ (Figure 2, top). Moreover, as the DBEincreasesfor the pyrrolic species (which form radical molecular ions, integer DBE) in the positive-ion APPI DBE distribution, the relative DBE abundance also increases in agreement with the nitrogen compound spectra.

\section{Ion Fragmentation}

Ion dissociation is more prevalent in APPI than ESI because of hot gases and radical ion formation. Fragmentation can be minimized (or eliminated) by proper choice of source pressure and tube lens voltage. The APPI source interfaces with the first stage of the mass spectrometer through a heated metal capillary (HMC) mounted to a custom-built adapter. At the exit of the HMC, an open-ended cylindrical tube (tube lens) focuses the ion flux in front of a conical skimmer. The skimmer is a pressure conductance limit (1-mm orifice) between the first stage of the mass spectrometer and the second stage that houses the first octopole ion guide/ trap. A convectron gauge senses the pressure in the first stage ( $\sim 2.1$ Torr for ESI conditions) and a direct current potential (350 V for ESI) is applied to the tube lens. Depending on the pressure and applied voltages in this region, ${ }^{\circ}$ ion $^{\circ}{ }^{\circ}$ ragmentation ${ }^{\circ}$ can $^{\circ}$ ensue $^{\circ}\left[22,{ }^{\circ} 23\right]$.

Table 2. List of DBE 9 positive-ion $\mathrm{N}_{1}$-class APPI species $\left(\mathrm{M}^{+}{ }^{\bullet}\right)$ and the DBE 9.5 negative-ion $\mathrm{N}_{1}$-class ESI species $(\mathrm{M}-\mathrm{H})^{-\mathrm{a}}$

\begin{tabular}{|c|c|c|c|c|}
\hline Experimental mass (Da) & Calculated error (ppm) & Ion molecular formula & DBE & Mass (Da) \\
\hline \multicolumn{5}{|l|}{ APPI $[M]^{+\bullet}$} \\
\hline 461.40162 & 0.04 & $\mathrm{C}_{33} \mathrm{H}_{51} \mathrm{~N}_{1}$ & 9 & 461.4016 \\
\hline 475.41720 & -0.11 & $\mathrm{C}_{34} \mathrm{H}_{53} \mathrm{~N}_{1}$ & 9 & 475.4173 \\
\hline 489.43289 & 0.02 & $\mathrm{C}_{35} \mathrm{H}_{55} \mathrm{~N}_{1}$ & 9 & 489.4329 \\
\hline 503.44869 & -0.27 & $\mathrm{C}_{36} \mathrm{H}_{57} \mathrm{~N}_{1}$ & 9 & 503.4486 \\
\hline 517.46428 & 0.15 & $\mathrm{C}_{37} \mathrm{H}_{59} \mathrm{~N}_{1}$ & 9 & 517.4642 \\
\hline \multicolumn{5}{|l|}{ ESI $[\mathrm{M}-\mathrm{H}]^{-}$} \\
\hline 460.39483 & -0.10 & $\mathrm{C}_{33} \mathrm{H}_{50} \mathrm{~N}_{1}$ & 9.5 & 460.3949 \\
\hline 474.41052 & -0.01 & $\mathrm{C}_{34} \mathrm{H}_{52} \mathrm{~N}_{1}$ & 9.5 & 474.4105 \\
\hline 488.42610 & -0.15 & $\mathrm{C}_{35} \mathrm{H}_{54} \mathrm{~N}_{1}$ & 9.5 & 488.4262 \\
\hline 502.44181 & -0.03 & $\mathrm{C}_{36} \mathrm{H}_{56} \mathrm{~N}_{1}$ & 9.5 & 502.4418 \\
\hline 516.45748 & 0.01 & $\mathrm{C}_{37} \mathrm{H}_{58} \mathrm{~N}_{1}$ & 9.5 & 516.4575 \\
\hline
\end{tabular}

aEach molecular formula [and the DBE value computed from it (eq 1)] is for the stated ion, not its neutral precursor. 


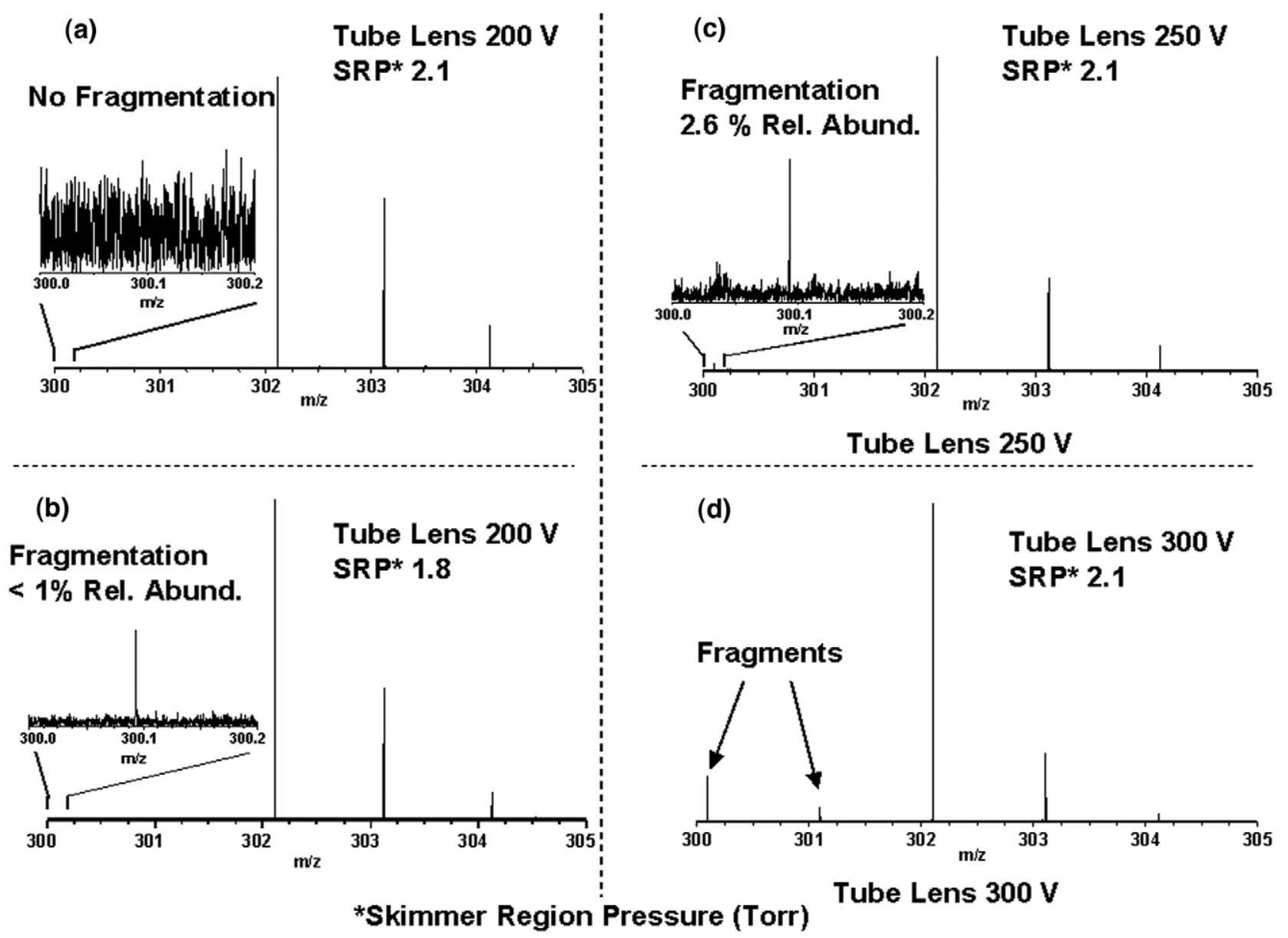

\begin{abstract}
Figure 6. Positive-ion APPI FT-ICR mass spectra of naphtho[2,3-a]pyrene $\left(\mathrm{C}_{24} \mathrm{H}_{14}\right.$, neutral monoisotopic mass, $302.110 \mathrm{Da}$ ) for various choices of tube lens voltage and skimmer region pressure. Fragmentation is evident at higher tube lens potential and/or lower pressure. At a tube lens potential of $200 \mathrm{~V}$ DC and a skimmer region pressure of 2.1 Torr, no fragmentation is observed.
\end{abstract}

The APPI source produces hot gas at the inlet of the $\mathrm{HMC}$, resulting in elevated gas temperature in the first stage (skimmer region) of the mass spectrometer and reduced pressure. Furthermore, tube lens voltage $>200$ $\mathrm{V}$ in combination with increased temperature for APPI can cause significant fragmentation.

The mass spectra of naphtho[2,3,a]pyrene $\left(\mathrm{C}_{24} \mathrm{H}_{14}\right)$ in Figure ${ }^{\circ}{ }^{\circ}$ at ${ }^{\circ}$ different $^{\circ}$ skimmer ${ }^{\circ}$ region ${ }^{\circ}$ pressures and ${ }^{\circ}$ tube lens ${ }^{\circ}$ voltages ${ }^{\circ}$ illustrate ${ }^{\circ}$ fragmentation. ${ }^{\circ}$ In ${ }^{\circ}$ Figure ${ }^{\circ} 6 a^{\circ}$ and $\mathrm{b}$, the tube lens voltage is held constant and the skimmer $^{\circ}$ region ${ }^{\circ}$ pressure ${ }^{\circ}$ is $^{\circ}$ raised $^{\circ}$ from $^{\circ} 1.8^{\circ}$ Torr $^{\circ}\left(\right.$ Figure $^{\circ} 6 \mathrm{~b}$ ) to $2.1^{\circ}$ Torr $^{\circ}$ (Figure ${ }^{\circ} 6 a^{\circ}{ }^{\circ}$ by $^{\circ}$ partial $^{\circ}$ valve $^{\circ}$ closure $^{\circ}$ at ${ }^{\circ}$ the vacuum pump. At 1.8 Torr, a fragmentation threshold is reached..$^{\circ}$ The $^{\circ}$ mass $^{\circ}$ scale-expanded ${ }^{\circ}$ inset $^{\circ}\left(\right.$ Figure $^{\circ} 6 \mathrm{~b}$ ) shows formation of $\left[\mathrm{C}_{24} \mathrm{H}_{12}\right]^{+}$, a fragment formed by the ${ }^{\circ}$ oss ${ }^{\circ}$ of ${ }^{\circ}$ two ${ }^{\circ}$ hydrogen atoms. ${ }^{\circ}{ }^{\circ}{ }^{\circ}$ Figure $^{\circ} 6 c^{\circ}$ and ${ }^{\circ} \mathrm{d}$, the skimmer region pressure is maintained at 2.1 Torr and the tube lens voltage is varied. At increased tube lens

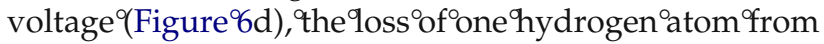
the monoisotopic precursor, $\left[\mathrm{C}_{24} \mathrm{H}_{13}\right]^{+\cdot}$ at mass $301 \mathrm{Da}$ is observed in addition to the loss of two hydrogen atoms (i.e., a $4.5 \mathrm{mDa}$ doublet is seen at $301 \mathrm{Da}$ ).

Furthermore, under conditions at which fragmenta- tion $^{\circ}$ occurs $^{\circ}$ (Figure $\left.{ }^{\circ} 6 \mathrm{~b}, \mathrm{c}, \mathrm{d}\right),{ }^{\circ}$ the ${ }^{\circ}$ magnitude $^{\circ}$ (zoom ${ }^{\circ}$ inset data not shown) of the $\left[\mathrm{C}_{24} \mathrm{H}_{14}+\mathrm{H}\right]^{+}$spectral peak relative to that of $\left[\mathrm{C}_{24} \mathrm{H}_{14}\right]^{+} \cdot$ decreases as fragmentation increases. All other spectra in this work were acquired under ${ }^{\circ}$ Figure $6 \mathrm{~A}^{\circ}$ conditions.

\section{Conclusions}

Positive-ion APPI spectra yield the same information as combined positive- and negative-ion ESI spectra for $\mathrm{N}_{1}$ class aromatics. Also, ESI and APPI mass analysis of a petroleum sample can yield aromatic core structural information. Although pyridinic and pyrrolic species ionization efficiency depends on the ionization method, APPI can generate positive ions for both pyridinic and pyrrolic compounds. The DBE values for the APPI positive-ion species differ by 0.5 for odd- and even-electron ions, and can distinguish pyrrolic from pyridinic nitrogen class species in a petroleum sample.

The APPI source uses a heated nebulizer $\left(300{ }^{\circ} \mathrm{C}\right)$ to form gas-phase analytes and thus increases the thermal 
energy of analyte and atmospheric gases in the source region. The increase in thermal energy changes the gas dynamics of the mass spectrometer and can induce fragmentation. Nevertheless, fragmentation of aromatics can be monitored and negated by proper choice of instrumental parameters. In this work, the good agreement in speciation of the aromatic nitrogen class species between a proven soft ionization technique (ESI) and APPI suggests that APPI can be conducted so as to virtually eliminate fragmentation.

\section{Acknowledgments}

This work was supported by National Science Foundation Grant DMR 00-84,173, Florida State University, and the National High Magnetic Field Laboratory in Tallahassee, FL 32310-4005.

\section{References}

1. Marshall, A. G.; Hendrickson, C. L.; Jackson, G. S. Fourier Transform Ion Cyclotron Resonance Mass Spectrometry: A Primer. Mass Spectrom. Rev. 1998, 17, 1-35.

2. Marshall, A. G.; Rodgers, R. P. Petroleomics: The Next Grand Challenge for Chemical Analysis. Acc. Chem. Res. 2004, 37, 53-59.

3. Rodgers, R.; Schaub, T.; Marshall, A. Petroleomics: MS Returns to Its Roots. Anal. Chem. 2005, 77, 20A-27A.

4. Zhan, D. L.; Fenn, J. B. Electrospray Mass Spectrometry of Fossil Fuels. Int. J. Mass Spectrom. 2000, 194, 197-208.

5. Rodgers, R. P.; Klein, G. C.; Stanford, L. A.; Kim, S.; Marshall, A. G. Characterization of Heavy, Biodegraded Crude Oils by High Resolution ESI FT-ICR Mass Spectrometry. Am. Chem. Soc. Abstr. 2004, 228, U654.

6. Rodgers, R. P.; Hendrickson, C. L.; Emmett, M. R.; Marshall, A. G. Reading Chemical Fine Print: Resolution and Identification of 3000 Nitrogen-containing Aromatic Compounds from a Single Electrospray Ionization Fourier Transform Ion Cyclotron Resonance Mass Spectrum of Heavy Petroleum Crude Oil. Energy Fuels 2001, 15, 492-498.

7. Robb, D. B.; Covey, T. R.; Bruins, A. P. Atmospheric Pressure Photoionization: An Ionization Method for Liquid Chromatography-Mass Spectrometry. Anal. Chem. 2000, 72, 3653-3659.

8. Syage, J. A.; Evans, M. D. Photoionization Mass Spectrometry. Spectroscopy 2001, 16, 14-21.
9. Tubaro, M.; Marotta, E.; Seraglia, R.; Traldi, P. Atmospheric Pressure Photoionization Mechanisms. 2. The Case of Benzene and Toluene. Rapid Commun. Mass Spectrom. 2003, 17, 2423-2429.

10. Raffaelli, A.; Saba, A. Atmospheric Pressure Photoionization Mass Spectrometry. Mass Spectrom. Rev. 2003, 22, 318-331.

11. Hughey, C. A.; Rodgers, R. P.; Marshall, A. G. Resolution of 11,000 Compositionally Distinct Components in a Single Electrospray Ionization Fourier Transform Ion Cyclotron Resonance Mass Spectrum of Crude Oil. Anal. Chem. 2002, 74, 4145-4149.

12. Purcell, J. M. Hendrickson, C. L. Rodgers, R. P. Marshall, A. G. Atmospheric Pressure Photoionization Fourier Transform Ion Cyclotron Resonance Mass Spectrometry for Complex Mixture Analysis. Anal. Chem. 2006, 78, 5906-5912.

13. Senko, M. W.; Hendrickson, C. L.; Pasa-Tolic, L.; Marto, J. A.; White, F. M.; Guan, S.; Marshall, A. G. Electrospray Ionization Fourier Transform Ion Cyclotron Resonance at 9.4 T. Rapid Commun. Mass Spectrom. 1996, 10, 1824-1828.

14. Rudzinski, W. E.; Aminabhavi, T. M.; Sassman, S.; Watkins, L. M Isolation and Characterization of the Saturate and Aromatic Fractions of a Maya Crude Oil. Energy Fuels 2000, 14, 839-844.

15. Håkansson, K.; Chalmers, M. J.; Quinn, J. P.; McFarland, M. A. Hendrickson, C. L.; Marshall, A. G. Combined Electron Capture and Infrared Multiphoton Dissociation for Multistage MS/MS in a Fourier Transform Ion Cyclotron Resonance Mass Spectrometer. Anal. Chem. 2003, 75, 3256-3262.

16. Marshall, A. G.; Verdun, F. R. Fourier Transforms in NMR, Optical, and Mass Spectrometry: A User's Handbook; Elsevier: Amsterdam, 1990.

17. Senko, M. W.; Beu, S. C.; McLafferty, F. W. Automated Assignment of Charge States from Resolved Isotopic Peaks for Multiply Charged Ions. J. Am. Soc. Mass Spectrom. 1995, 6, 52-56.

18. Emmett, M. R.; Caprioli, R. M. Micro-Electrospray Mass Spectrometry: Ultra-high-sensitivity Analysis of Peptides and Proteins. J. Am. Soc Mass Spectrom. 1994, 5, 605-613.

19. McLafferty, F. W.; Turececk, F. Interpretation of Mass Spectra; 4th ed.; University Science Books: Mill Valley, CA, 1993.

20. Rapp, U.; Staab, H. A.; Wunsche, C. NIST 2005 [NIST/EPA/NIH Mass Spectral Library 2005 (Upgrade)]; Wiley: Hoboken, NJ, 2005.

21. Hughey, C. A.; Hendrickson, C. L.; Rodgers, R. P.; Marshall, A. G.; Qian K. Kendrick Mass Defect Spectrum: A Compact Visual Analysis for Ultrahigh-Resolution Broadband Mass Spectra. Anal. Chem. 2001, 73, 4676-4681.

22. Hagman, C.; Tsybin, Y. O.; Håkansson, P. Solution-phase Deuterium/ Hydrogen Exchange at a Specific Residue Using Nozzle-Skimmer and Electron Capture Dissociation Mass Spectrometry. Rapid Commun. Mass Spectrom. 2006, 20, 661-665.

23. Loo, J. A.; Edmonds, C. G.; Smith, R. D. Tandem Mass-Spectrometry of Very Large Molecules-Serum-Albumin Sequence Information from Multiply Charged Ions Formed by Electrospray Ionization. Anal. Chem. 1991, 63, 2488-2499. 